\title{
POLYIMIDE DIELECTRIC LAYER ON FILAMENTS FOR ORGANIC FIELD EFFECT TRANSISTORS: CHOICE OF SOLVENT, SOLUTION COMPOSITION AND DIP-COATING SPEED
}

\author{
Lina Rambausek ${ }^{1}$ Els Bruneel², Gilbert De Mey $^{3}$, Lieva Van Langenhove ${ }^{4}$ \\ ${ }^{1}$ Ghent University - Department of Textiles, Ghent, Belgium, Technologiepark 907, 9052 Zwijnaarde, \\ tel +32 926454 06, fax +32 926458 31, Lina.Rambausek@UGent.be \\ ${ }^{2}$ Ghent University - Department of Inorganic and Physical Chemistry, Ghent, Belgium, Krijgslaan 281 S3, 9000 Ghent, \\ tel. +32 926444 47, fax +32 926449 83, Els.Bruneel@UGgent.be \\ ${ }^{3}$ Ghent University - Electronics and Information Systems Department, Ghent, Belgium, Sint-Pietersnieuwstraat 41, 9000 Ghent, \\ tel. +32 926433 86, fax +32 926435 94, Gilbert.DeMey@UGent.be \\ ${ }^{4}$ Ghent University - Department of Textiles, Ghent, Belgium, Technologiepark 907, 9052 Zwijnaarde, \\ tel +32 926454 06, fax +32 926458 31, Lieva.VanLangenhove@UGent.be
}

\begin{abstract}
:
In today's research, smart textiles is an established topic in both electronics and the textile fields. The concept of producing microelectronics directly on a textile substrate is not a mere idea anymore and several research institutes are working on its realisation. Microelectronics like organic field effect transistor (OFET) can be manufactured with a layered architecture. The production techniques used for this purpose can also be applied on textile substrates. Besides gate, active and contact layers, the isolating or dielectric layer is of high importance in the OFET architecture. Therefore, generating a high quality dielectric layer that is of low roughness and insulating at the same time is one of the fundamental requirements in building microelectronics on textile surfaces. To evaluate its potential, we have studied polyimide as a dielectric layer, dip-coated onto copper-coated polyester filaments. Accordingly, the copper-coated polyester filament was dip-coated from a polyimide solution with two different solvents, 1-methyl-2pyrrolidone (NMP) and dimethylformaldehyde. A variety of dip-coating speeds, solution concentrations and solventsolute combinations have been tested. Their effect on the quality of the layer was analysed through microscopy, leak current measurements and atomic force microscopy (AFM). Polyimide dip-coating with polyimide resin dissolved in NMP at a concentration of $15 \mathrm{w} \%$ in combination with a dip-coating speed of $50 \mathrm{~mm} / \mathrm{min}$ led to the best results in electrical insulation and roughness. By optimising the dielectric layer's properties, the way is paved for applying the subsequent semi-conductive layer. In further research, we will be working with the organic semiconductor material TIPS-Pentacene
\end{abstract}

\section{Keywords:}

dip-coating, dielectric, polyimide, polyester filament, fibrous, smart textiles, thin film, transistor

\section{Introduction}

The idea of integrating electronic functions into textiles has been present in the minds of product developers and designers for decades. In 1932, the concept of electrically heated clothing for police officers was introduced [1]. In 1966, the designer Diana Dew integrated light into fashion items [2,3]. Hence, the concept of smart textile systems and intelligent clothing has obviously been a much discussed topic for more than half a century.

From the start, both industries, microelectronics and textiles, saw the unique chance for new business opportunities in this quickly developing application field, including wearable electronics. Especially for the European textile industry, high-tech products like smart textiles might be one of the last straws to clutch at before moving production to lower-wage countries [4].

Initially, electronics were integrated into textile structures on a low-tech level by simply attaching rigid microelectronic devices [5]. After some time and many unsuccessful (or failed) products [5], it became clear that customers are not satisfied with unreliable gadget-like items. They ask for more advanced solutions, i.e. electronic devices invisibly integrated into their surroundings [6]. Today, research and industry strive for truly integrated electronic functions. Therefore, research is trying to find ways to construct electronic devices directly into or onto the textile substrate like fibres or filaments.

Many microelectronic components, e.g. transistors, light emitting diodes (LED) or memory, are built up in layers, which are deposited in a variety of ways. By entering into the new application field of textile electronics, the processes through which the different layers in microelectronics are applied need to be revised and adopted for the application in textile substrates. As with flexible electronics, the properties that come along with the textile's nature, e.g. having small dimensions or being flexible, stretchable or drapable and sometimes cylindrical, provide for a challenging assignment [7]. 
A transistor is an example of a microelectronic active component with a layered architecture. There are different ways of constructing a transistor. Here we only refer to the TopContact-Bottom-Gate (TCBG) layout (see Figure 1-3). As for the working principle of the organic field effect transistor (OFET), a voltage is applied to the gate layer. The current flows from source to drain contact, crosses the semi-conductive layer and flows at the interface of the dielectric layer and semiconductor.

The gate layer was thoroughly investigated by Schwarz et al. (2010) [8]. The focus of this work is on the dielectric layer, which plays a significant role in the performance of microelectronic devices in general, for instance field effect transistors, LED or photovoltaic cells.

In the layered architecture presented here, the thickness of the dielectric layer determines the voltage to be applied (turn-on voltage) and, partly, the performance (field efficiency) of the transistor. The thicker the layer, the more voltage needs to be applied to turn the transistor on, causing the current to flow from source to drain contact. The roughness of the dielectric layer influences the mobility of the electrons flowing through it (carrier mobility), and therefore the switching speed (on/ off ratio) of the transistor. A potential end application of a

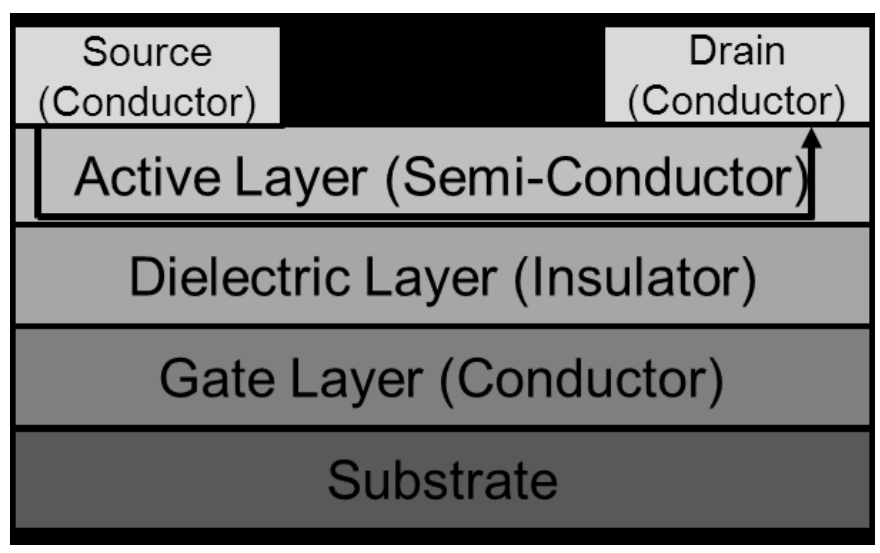

Figure 1. Schematic view of organic field effect transistor Top-ContactBottom-Gate architecture. fibrous transistor points at wearable electronics; therefore, performance at low voltage is preferred to prevent the wearer from being endangered. Hence, achieving a very thin and at the same time insulating layer is important and the aim of this study.

The roughness of the dielectric layer not only affects the mobility but also the molecular ordering of the subsequently applied semiconductor during solidification [9]. When the semiconductor self-assembles after depositing on the dielectric layer, a higher roughness can lead to the formation of voids and defects in the semi-conductive layer. Therefore, the layer's roughness and inhomogeneity might lead to traps for charge carriers, which will decrease the performance of the transistor. Roughness, in addition to the overall morphology, is therefore a good performance indicator and hence crucial to the performance of the final device $[10,11]$. The roughness of the layer investigated in this study will be discussed in detail in a subsequent publication.

Like in many other microelectronic devices, a dielectric layer that fits the requirements of the device is fundamental for OFETs. In the present case, this means a layer as thin as possible, but still electrically insulating. To meet these requirements, many inorganic but also organic materials have been assessed for their suitability as dielectric layers [12-16]. Within the OFET architecture, this layer completes the task of electrically insulating the gate layer from semi-conductive layer.

In general, polymeric materials used as dielectric are the perfect match for textile substrates. These organic materials offer the right flexibility and processing technique. Polymers seem to be highly promising because of their textile compatible properties, but also because they are processable in solution.

As early as in the late 1970s, polyimide (PI) films were used as dielectric layers in electronics [17]. But even earlier, high quality isolating layers that met the ever-increasing demand in the field of thin film microelectronics were a recurring subject in research. Youngs et al. (2006) [18] showed that globally the absolute volume of publications on dielectrics has

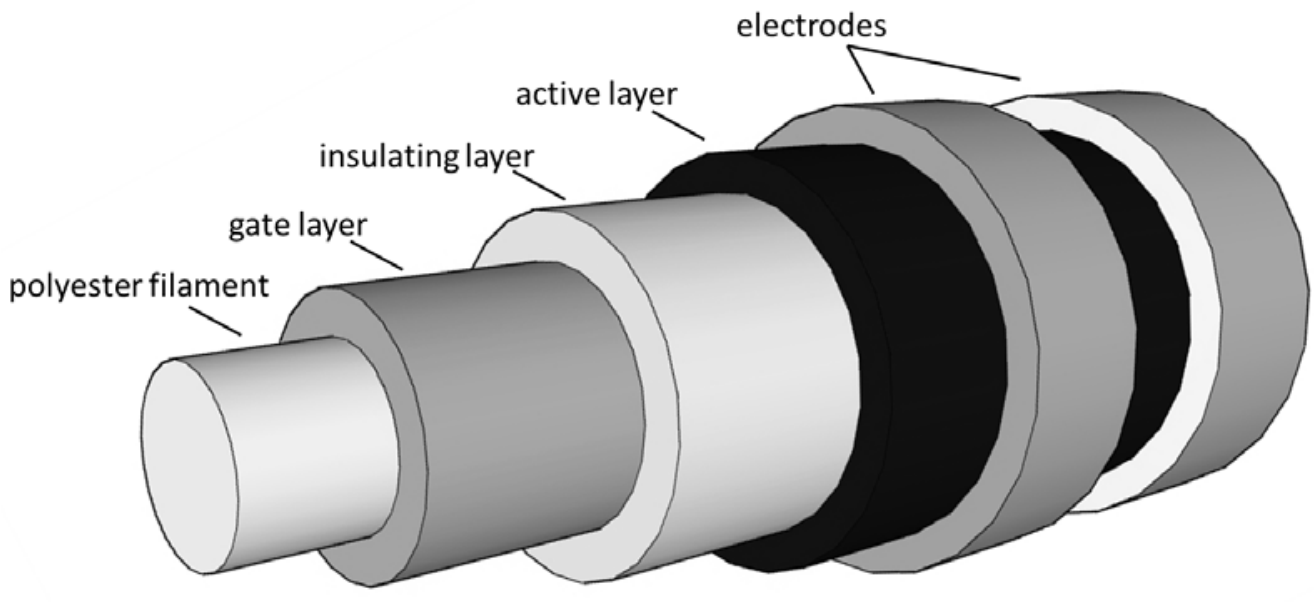

Figure 2. Schematic view: organic field effect transistor Top-Contact-Bottom-Gate architecture on a filament. 
been steadily increasing throughout the years leading to the conclusion that research still needs to solve many issues in this field. Much discussed topics in this respect are high permittivity (high k) dielectrics for electronics applications and the role of the interfaces in-between the different layers [9]. The top three application areas for research, with respect to dielectric materials in 2004 , are related to capacitors, insulators and transistors [18]. As mentioned, the last is the subject of this publication

Many solutions have been found for depositing a perfected dielectric layer on rigid flat substrates. This includes application via different coating processes like evaporation or etching processes, spin-coating, nano-imprinting, ink-jet printing, spray coating, drop casting and screen printing [10]. Often those processes are discontinuous.

Today, in the age of smart textiles and flexible electronics, research needs to find solutions to achieve this on textile substrates often having a cylindrical shape and roughness that the electronics industry is not used to dealing with. The new substrate type determines the choice of the production steps and materials. Because of the nature of the substrate, here a polyester (PES) filament with a diameter of $888 \mu \mathrm{m}$, only continuous production processes are perceived as valuable for further investigation. In addition, process integration into today's textile production lines needs to be considered, and so low temperature and wet, eventually solution-based processes seem to be the best choice. The insulating layer should have similar mechanical properties as the substrate in order to allow bending and stretching during the final textile integration, e.g. by weaving $[7,19]$. In addition, the dielectric layer should also prevent degradation of the underlying layer by being waterproof and inhibiting oxidation [20].

In 2007, Cardoen successfully deposited a dielectric layer on copper-coated PES ribbons by dip-coating [20]. This process can easily be up-scaled from lab conditions to mass production [5]. However, the resulting layers suffered from inhomogeneities and a rough cellular surface. Initially, the results were not satisfactory but since dip-coating is perceived as the process that is the most adequate to treat fibrous substrates, the process parameters will be optimised to find the best process conditions.

This paper deals with the following factors: dip-coating speed, choice of solvent and solvent-solute content of the dip-coating bath. Spin coating or other techniques as vapour deposition were excluded from investigation since this research focuses on textile applicable processes, which also means processes that can be applied on a cylindrical shaped substrate [12]. High temperature or vacuum process techniques are not optimal to be used in textile production processes due to, for example, the substrate's shape. Besides, they are difficult to up-scale since they are discontinuous processes.

The application of the polymeric material as a dielectric layer on a flexible, cylindrical substrate involves hundreds of hurdles in processing. This includes the entire process chain, starting from storage of the substrate to the final analysis of the deposited layer. In this paper, only a glimpse into these difficulties can be given.

As mentioned, the paper deals with the deposition of a $\mathrm{PI}$ dielectric layer by dip-coating and its optimisation. Several crucial influencing factors are discussed, such as choice of solvent, percentage of solute content and dip-coating speed. Other process conditions like pre-treatment of the substrate, ambient humidity and the drying process do affect the layer formation and were also tested. These factors are however not a subject of this particular publication.

By finding and optimising the optimal dip-coating parameters for applying the dielectric PI layer onto the filament, opportunities are provided for subsequent perfection of the semiconductor layer, the next step in constructing a fibrous OFET. The textile industry is used to working with wet processes during production and therefore dip-coating can be integrated without difficulty. In comparison with lithography, subtractive processes and vacuum-based film deposition, dip-coating is a technique in which materials are efficiently used, which saves time and costs [10].

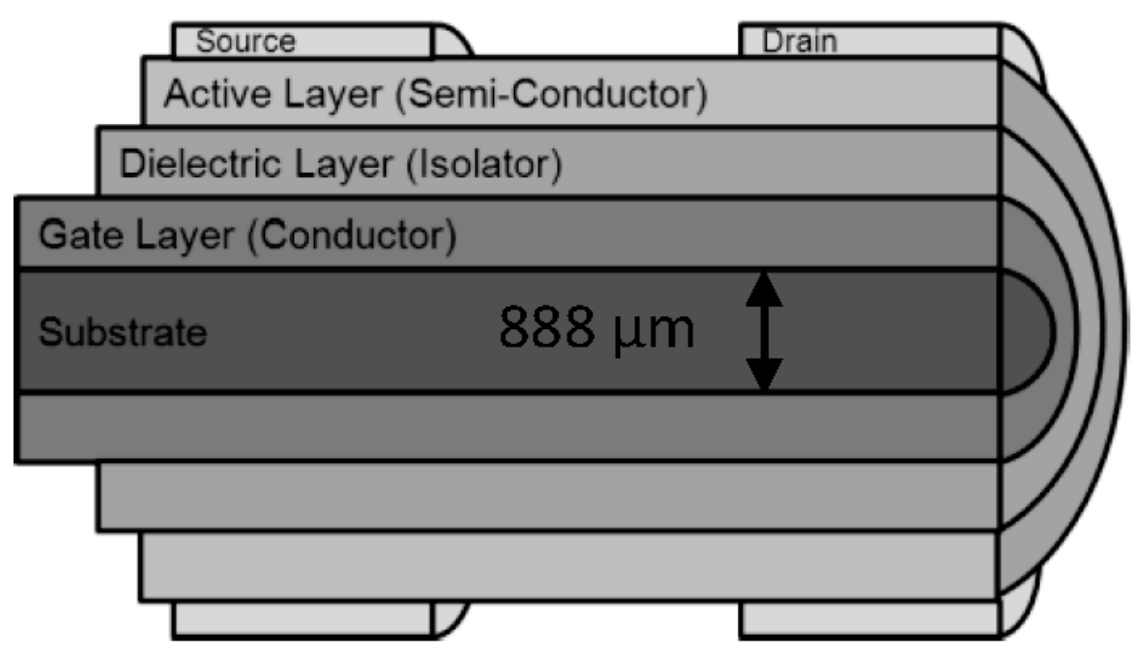

Figure 3. Schematic view of cross-section: organic field effect transistor architecture on filament. 
This paper assists in understanding the relationships of the different materials used in textile microelectronic devices and might be an eye-opener for future opportunities in textile applications.

\section{Materials}

In this study, a PI resin, purchased from Alfa Aesar, was chosen to be applied as an insulating dielectric layer onto a PES filament that prior to this had been coated with copper. The PES filament had an $888 \mu \mathrm{m}$ diameter and was purchased from Teijin.

In particular, $\mathrm{PI}$ was chosen as the dielectric material because of its good flexibility [12], low conductivity, high breakdown voltage and high dielectric constant. In addition, it is compatible with wet processing $[13,21]$. This is an advantage because wet processes are frequently used in the textile industry that cover pre-treatment, printing, dyeing and finishing [22] and therefore also dip-coating. Furthermore, its biocompatibility is a plus when considering applications close to the skin.

The chemical structure of $\mathrm{PI}$ is given in Figure 4. PI films are commercially available, for example as Kapton Film (DuPont) [23], and are frequently used in the electronics industry.

Imides normally exist as monomers. These monomers can be transferred into PI by imidisation, a reaction between for example a dianhydride and a diamine. The polymer we used comes as a powder and has the advantages of being fully imidised, soluble in a variety of solvents and processable at low temperatures. According to the producers, coating with PI results in a durable and tough layer. PI has an excellent chemical stability and shows good adhesion to various surfaces [24].

The dielectric constant of PI varies with temperature. At $150^{\circ} \mathrm{C}$, its dielectric constant is approximately 3.5 , whereas it decreases to 3.02 at $350^{\circ} \mathrm{C}$ [12]. The dielectric constant is an indicator for the insulating properties of the material. $\mathrm{PI}$ is stable towards most of the common solvents, unlike other polymers, e.g. polyethylene or PES $[25,26]$. This is an important prerequisite for subsequent deposition of the organic semiconductor.

The polymer can be solution-processed from a limited number of solvents, e.g. 1-methyl-2-pyrrolidone (NMP) $[12,20,27]$ and dimethylformaldehyde (DMF) [28-30]. Both solvents, NMP and DMF, are studied in this paper and were purchased from Sigma Aldrich.

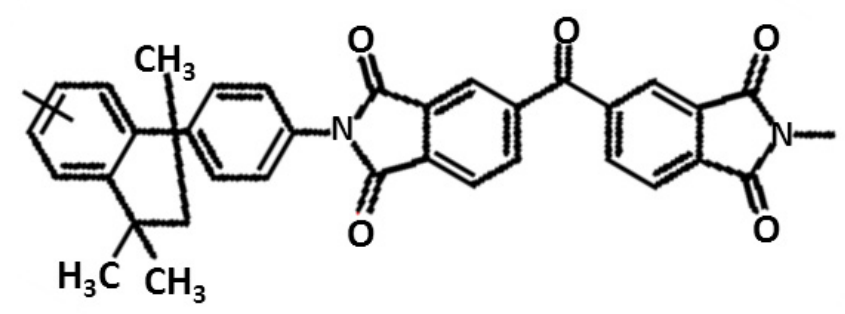

Figure 4. Chemical structure of polyimide resin [24].
The quality of the dielectric layer was evaluated by determining its insulating properties through resistivity and leak current measurements. The insulating properties were demonstrated by Maccioni et al. who used a cylindrical metal fibre with a uniform PI layer of $1 \mu \mathrm{m}$ (purchased from Elektrisola) indicating a leak current of less than 10-10 A [31]. A theoretical value of $550 \mathrm{~nm}$ for the insulating layer thickness with a leak current of 10-9 A was defined by PROETex (2007) [13].

\section{Methods}

Dip-coating has been chosen for the deposition of the dielectric layer onto the filament substrate. First, the substrate undergoes a cleaning step, subsequently it is dip-coated into the solution at a controlled speed (withdrawal speed), followed by a drying period at $60^{\circ} \mathrm{C}$ for $24 \mathrm{~h}$, as recommended by the producers of the $\mathrm{PI}$ resin. When the substrate is withdrawn from the dipcoating bath, the polymer solution adheres to its surface and solidifies during drying (Figure 5) [32]. The schematic drawing in Figure 5 shows a dip-coating device.

As mentioned earlier, the dip-coating process allows up-scaling for continuous production on an industrial scale (see Figure 6); devices already exist and are well established in today's textile industry's production lines. The properties of the dip-coated layer in terms of thickness and quality are determined by temperature, pressure, humidity and speed. Also the angle of withdrawal, pre-treatment of the substrate and drying conditions play a significant role $[33,34]$. In this publication, we only refer to the dip-coating parameter speed; withdrawal was undertaken at $90^{\circ}$ to achieve an even layer surrounding the substrate.

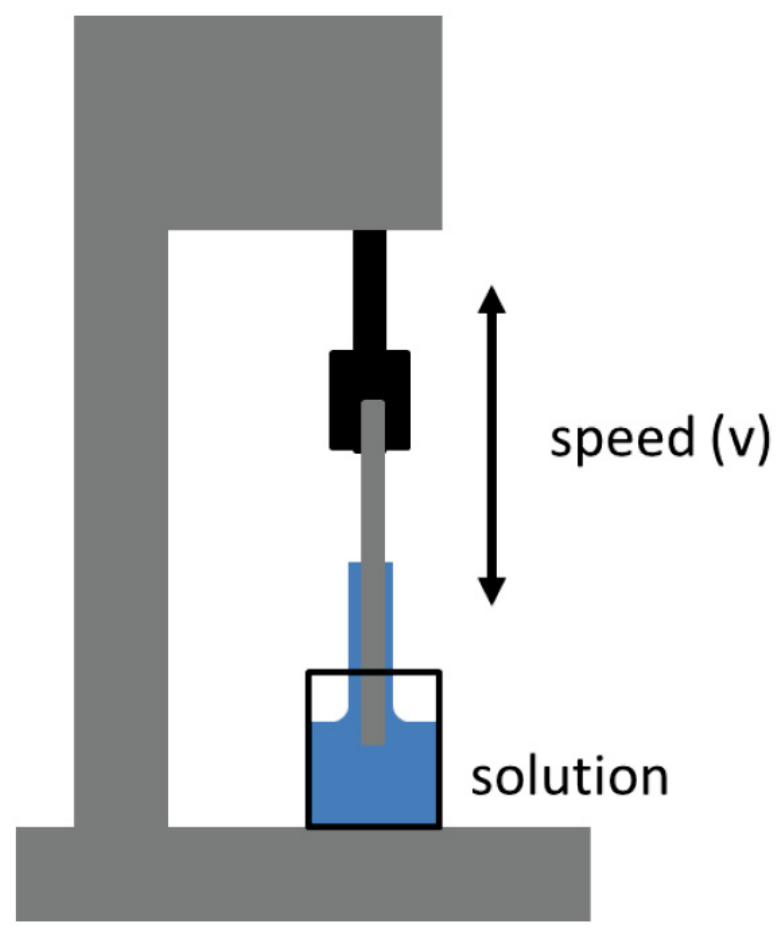

Figure 5. Discontinuous dip-coater (schematic drawing). 


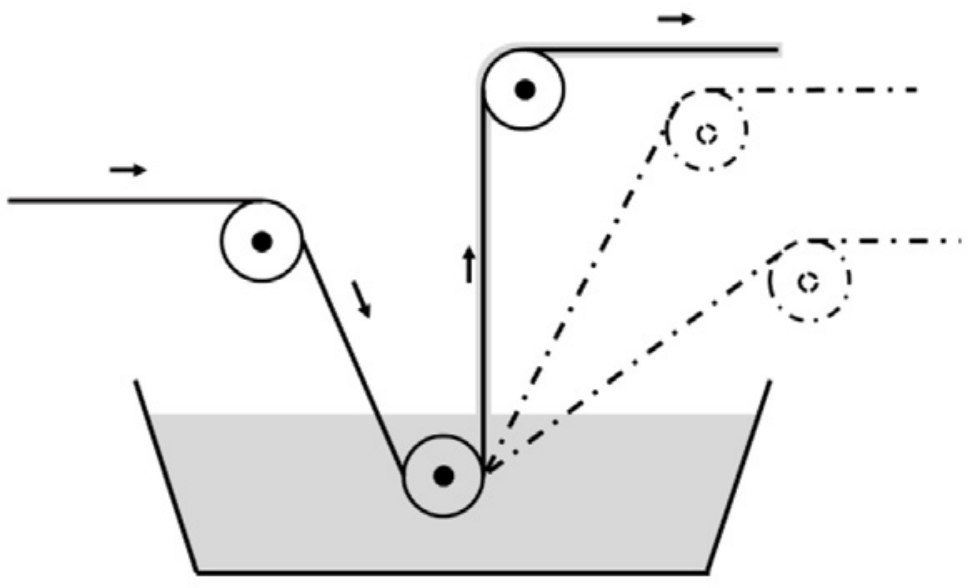

Figure 6. Continuous dip-coating process indicating the variation in withdrawal angles.

As mentioned before, for the dip-coating bath, $\mathrm{PI}$ resin is dissolved in two different solvents as suggested in literature, DMF [20] and NMP [12]. The choice of the solvent determines the evaporation rate from the solution. Both solvents are high boiling point solvents whereas DMF has a slightly lower boiling point than NMP, $153^{\circ} \mathrm{C}$ and $204^{\circ} \mathrm{C}$, respectively. The speed at which the solvent evaporates from the deposited layer has an impact on the layer quality during the process of solidification [32].

A variety of concentrations were tested. For DMF, this relates to a range from $7.5 \mathrm{w} \%$ to $17.5 \mathrm{w} \%$, gradually increased in intervals of $2.5 \mathrm{w} \%$. The dip-coating withdrawal speed ranged from 1 to $150 \mathrm{~mm} / \mathrm{min}$. For NMP solutions, ranges were adopted based on the results of the DMF coatings.

The effects on the layer properties were investigated by measuring the thickness of the layer, conducting an electrical characterisation and performing microscopic analysis. The thickness of the dielectric layer was measured by embedding the substrate in historesin (Leica) and by subsequent microscopic analysis. Electrical characterisation included measurements of layer resistivity and leak current.

For evaluating the electrical properties of the layer, the four point probe resistivity measurement was applied. The four probes are applied on the filament in a linear fashion. The current is supplied on the outer probes and the voltage is measured between the inner probes; therefore, a voltage drop can be detected across the inner probes. Through this arrangement, only the resistance of the layer itself is measured. Based on the measurements, the resistance or conductivity can be calculated through:

$$
R=\frac{\text { Voltage }}{\text { Current }}=\frac{U}{I}
$$

For the measurement, an Ampere meter (Fluke 75 Series II multimeter) with a resolution of $0.01 \mathrm{am}$, a DC power supply (Tti PL601) and a voltmeter (Digi tool IEC 1010 Digi 16) with a resolution of $0.1 \mathrm{mV}$ were used. The probes were flat alligator clamps (RS Components) assembled at a predetermined distance on a holder to ensure constant distance during measuring (Figure 7). The distance between the outer probes is $35 \mathrm{~mm}$. The two inner probes are arranged at a distance of $25 \mathrm{~mm}$. This custom made setup allowed reproducible resistance measurements.

As for the leak current measurements, two contacts were used on predefined locations on the sample. One alligator clamp was placed on the conductive copper layer of the samples at $10 \mathrm{~mm}$ from the point where the isolating coating starts. The other clamp was positioned at a distance of $20 \mathrm{~mm}$, exactly 10 $\mathrm{mm}$ from the other side on the isolating layer, as indicated in Figure 8.

Silver-based conductive adhesive Shieldokit 3980 from the company Holland Shielding Systems was applied on the samples to generate a good contact between clamp and $\mathrm{PI}$ layer, ensuring that the isolating properties arose from the dielectric layer and not from a bad contact. The threshold value for the insulating properties of the dielectric layer was a resistance of $200 \mathrm{M} \Omega$.

Those samples that showed good insulating properties were selected for further investigation of their insulating properties. For the following measurements, a gold contact was sputtered onto the dielectric layer using vacuum gold deposition. The gold electrodes have a surface area that is representative of the source and drain contacts in the OFET architecture, which are not part of this publication. Shadow masking using tape was employed to make contacts with a length of $20 \mathrm{~mm}$. During the evaporation process, the backside of the fibres is not completely coated, unlike the top and the sides of the fibre. Assuming that $240^{\circ}$ of the fibre's circumference will be coated for fibres with an $888 \mu \mathrm{m}$ diameter, this leads to a surface area of approximately $74 \mathrm{~mm}^{2}$.

The gold electrodes not only make a much closer contact to the interface, but also extend over a larger surface area compared with the alligator clamps. The measurement was now done by 

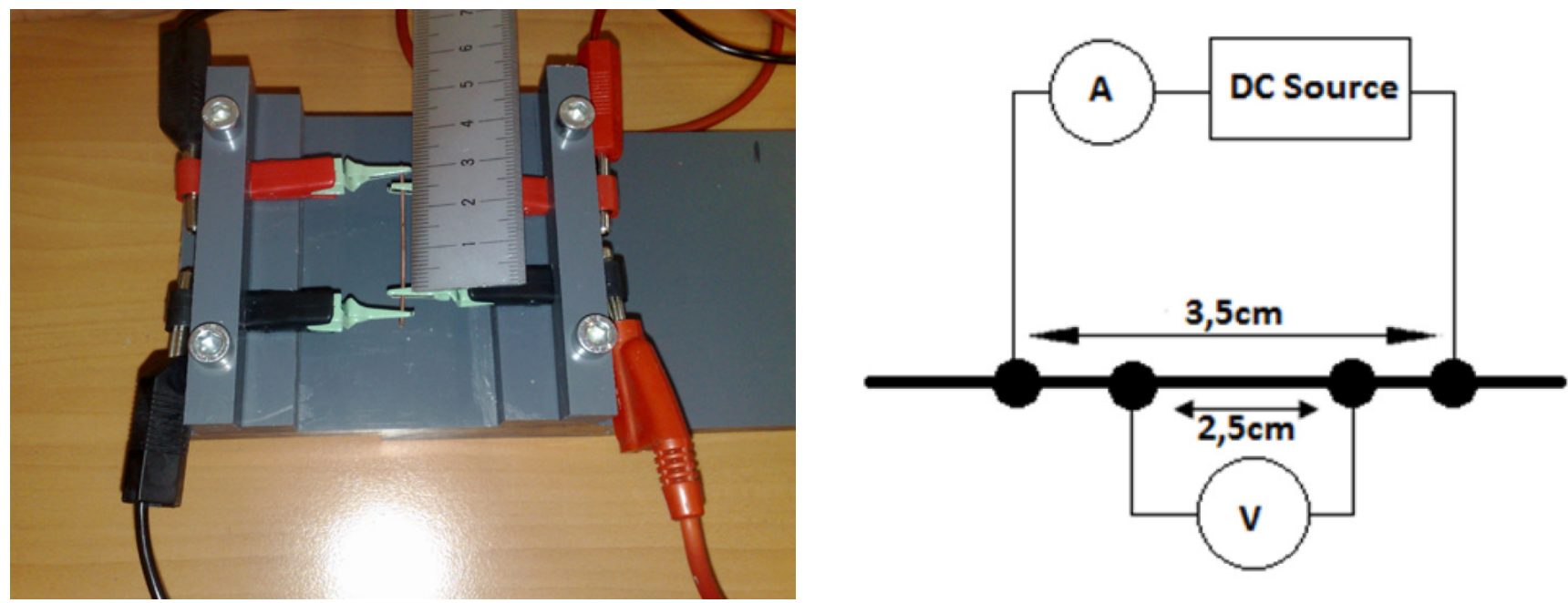

Figure 7. Image of a setup with four flat alligator clamps to make contact (left) and schematic representation (right).

measuring the current leakage through the dielectric layer at an increasing voltage between the gate copper contact and gold deposited contact. This was initially done with an accuracy of 10-5 A and 10-4 V. The maximum generated voltage was $60 \mathrm{~V}$. Samples should be isolating over the entire range. Final tests were conducted at increased sensitivity up to the level of pA. Voltage was increased from 0 to $10 \mathrm{~V}$ in stages of $1 \mathrm{~V}$.

\section{Results and Discussion}

\section{Dip-coating from PI/DMF solution}

Resistivity measurements were conducted as described above. The insulating properties of the dielectric layer are shown in Table 1. The layer thickness is displayed for different withdrawal speeds and solute concentration of DMF in the same table.

The results show that the layer thickness increases with an increasing solute concentration (in w\%) and increasing withdrawal speed (in $\mathrm{mm} / \mathrm{min}$ ). When coated at a lower concentration of $7.5 \mathrm{w} \%$ as well as $10 \mathrm{w} \% \mathrm{PI}$, all samples remain conductive over the entire range of withdrawal speed (threshold $<1010 \Omega \mathrm{cm}$ ) [8]. Insulating layers were only obtained at a concentration of $12.5 \mathrm{w} \%$, when the dip-coating speed was relatively low, i.e. $50 \mathrm{~mm} / \mathrm{min}$. A cross-section of the filament displaying also the previously deposited gate layer is shown in Figure 9.

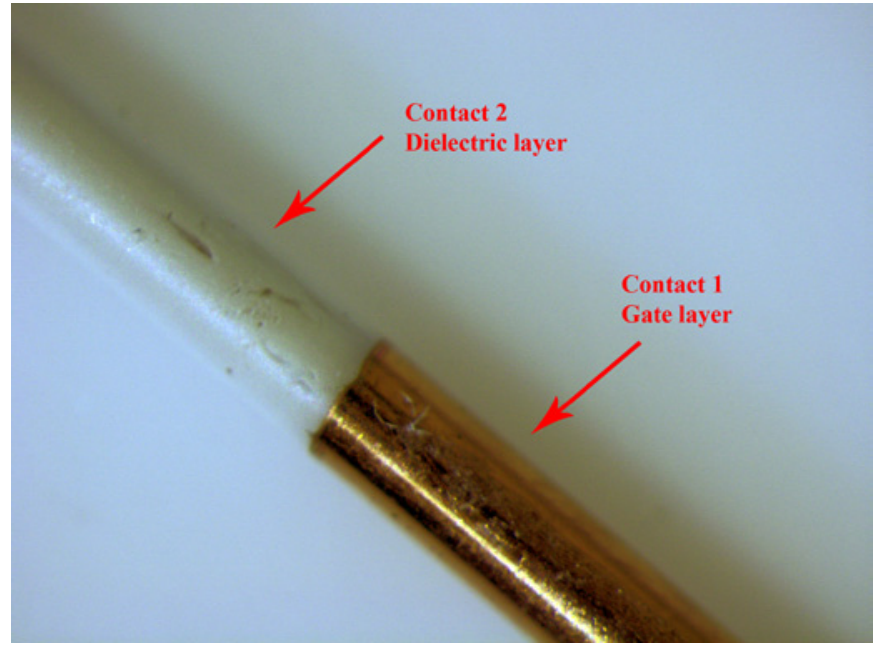

Figure 8. Representation of position of contact points for determination of leak current through a dielectric layer.

It was observed that the lower the solute concentration, the higher the dip-coating speed needs to be to achieve an insulating layer. At a concentration of $15 \mathrm{w} \%$, an isolating layer could already be achieved at a withdrawal speed of $10 \mathrm{~mm} /$ min, as shown in Table 1.

As for the concentration of $17.5 \mathrm{w} \%$, all tested withdrawal speeds resulted in an isolating layer. To visualise the trend, the

Table 1.Thickness (in $\mu \mathrm{m}$ ) of dielectric layer at different withdrawal speeds $v$ (in $\mathrm{mm} / \mathrm{min}$ ) versus polyimide concentration in dimethylformaldehyde (in w\%). Shaded fields indicate conductivity (Cond) (threshold $<10^{10} \Omega \mathrm{cm}[8]$ ).

\begin{tabular}{|c|c|c|c|c|c|c|c|c|c|c|}
\hline $\begin{array}{c}{[\mathbf{m m} /} \\
\mathbf{m i n}] \\
{[\mathbf{w} \%]}\end{array}$ & $\mathbf{1}$ & $\mathbf{5}$ & $\mathbf{7 . 5}$ & $\mathbf{1 0}$ & $\mathbf{1 2 . 5}$ & $\mathbf{2 5}$ & $\mathbf{5 0}$ & $\mathbf{7 5}$ & $\mathbf{1 0 0}$ & $\mathbf{1 5 0}$ \\
\hline 7.5 & Cond & Cond & Cond & Cond & Cond & Cond & Cond & Cond & Cond & Cond \\
\hline 10.0 & Cond & Cond & Cond & Cond & Cond & Cond & Cond & Cond & Cond & Cond \\
\hline 12.5 & 0.21 & 0.26 & 0.57 & 0.53 & 0.56 & 0.61 & 0.86 & 2.07 & 2.19 & 4.28 \\
\hline 15.0 & 0.25 & 0.32 & 0.56 & 0.88 & 1.09 & 1.36 & 2.83 & 3.64 & 7.65 & 7.45 \\
\hline 17.5 & 1.53 & 1.60 & 1.96 & 2.76 & 8.70 & 9.01 & 9.20 & 9.95 & 12.83 & 15.47 \\
\hline
\end{tabular}




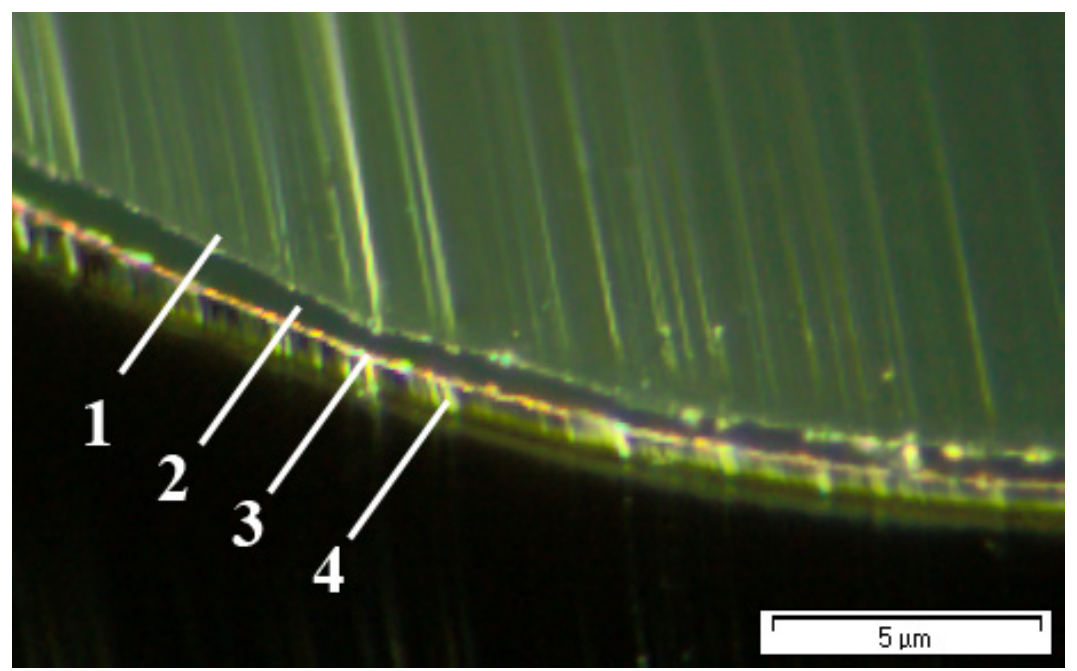

Figure 9. Microscopic picture of fibrous transistor cross-section. The picture shows the polyester filament (1), the gate layer (2+3) and dielectric layer coated from $15 \mathrm{w} \%$ polyimide/dimethylformaldehyde solution at $75 \mathrm{~mm} / \mathrm{min}$ (4) [35].

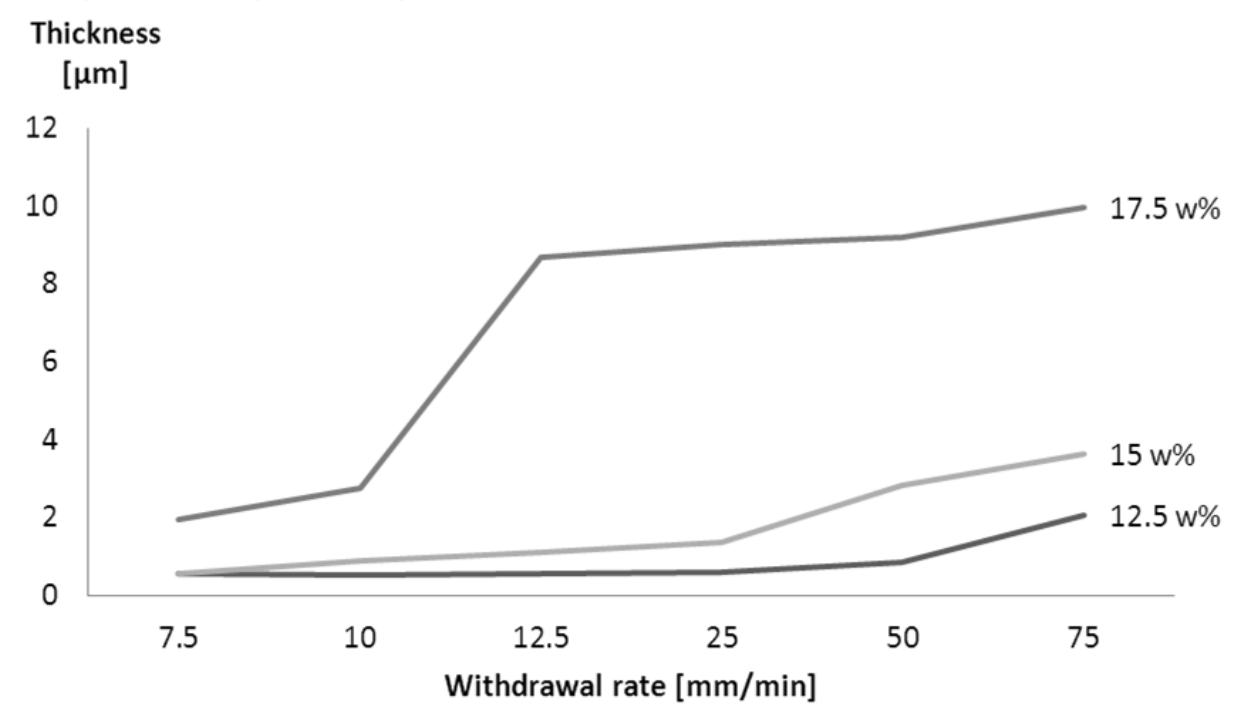

Figure 10. Thickness of dielectric layer as a function of the withdrawal rate at concentrations $12.5 \mathrm{w} \%, 15 \mathrm{w} \%$ and $17.5 \mathrm{w} \%$ polyimide in dimethylformaldehyde.

results are represented in Figure 10. A clear increasing trend in thickness was observed upon increasing the withdrawal speed.

\section{Dip-coating from PI/NMP solution}

Following the analysis of the DMF solution, NMP was also investigated as a potential solvent. As reported in literature, the use of higher boiling point solvents affects the morphology and therefore the properties of the deposited layer [36-38]. During the solvent evaporation, molecules are given more time to selfassemble; therefore, NMP, which has a boiling point of $202^{\circ} \mathrm{C}$ [39], was chosen as an alternative solvent for DMF. The boiling point of DMF is only $153^{\circ} \mathrm{C}$ [40] under standard atmospheric conditions and, hence, the solution with NMP could lead to better results.
Also in this testing series, the withdrawal speed was varied from 1 to $150 \mathrm{~mm} / \mathrm{min}$. An overview of the measured thicknesses for samples coated from $12.5 \mathrm{w} \% \mathrm{DMF}$, and NMP for comparison, is given in Table 2. For NMP solutions, it also is applicable that with increased concentration the thickness increases and therefore the insulating properties of the layer improve. It could be observed that in the case of NMP, the thickness was lower when compared with DMF at the same withdrawal speed and concentration. This effect became more pronounced at higher withdrawal speeds. Coatings at a concentration of $12.5 \mathrm{w} \%$ and a speed of $25 \mathrm{~mm} / \mathrm{min}$ and higher were insulating. When comparing the test results in the DMF series with those of the NMP series (see Table 2), we can conclude that a threshold thickness near $600 \mathrm{~nm}$ is required for the PI layer to become insulating.

Table 2. Thickness (in $\mu \mathrm{m}$ ) of dielectric layer at different withdrawal speeds (in $\mathrm{mm} / \mathrm{min}$ ) versus dimethylformaldehyde (DMF) or 1-methyl-2-p (NMP) as a solvent at a constant concentration of $12.5 \mathrm{w} \%$ polyimide. Shaded fields indicate conductivity (threshold $<10^{10} \Omega \mathrm{cm}$ ) [8].

\begin{tabular}{|c|c|c|c|c|c|c|c|c|c|c|c|}
\hline $\begin{array}{c}\text { [mm/min] } \\
\text { solvent }\end{array}$ & $\mathbf{1}$ & $\mathbf{5}$ & $\mathbf{7 . 5}$ & $\mathbf{1 0}$ & $\mathbf{1 2 . 5}$ & $\mathbf{2 5}$ & $\mathbf{5 0}$ & $\mathbf{7 5}$ & $\mathbf{1 0 0}$ & $\mathbf{1 5 0}$ & \\
\hline DMF & 0.21 & 0.26 & 0.57 & 0.53 & 0.56 & 0.61 & 0.86 & 2.07 & 2.19 & 4.28 & $\mu \mathrm{m}$ \\
\hline NMP & 0.18 & 0.23 & 0.26 & 0.27 & 0.57 & 0.58 & 0.78 & 0.88 & 1.24 & 1.28 & \\
\hline
\end{tabular}


In addition to the resistivity measurements, the leak current between the gate layer and one contact electrode applied on the surface of the dielectric layer was investigated. Only those samples that have been tested over the entire range of the DC generator (up to $60 \mathrm{~V}$ ) are tested with the same setup but with more exact tools than the multimeter, which has only an accuracy of 10-5 A. The HP LF Impedance Analyser 4192A can measure up to 10-14 A accuracy. Earlier, the contacts on the layer were applied in silver ink; the next series of contacts consisted of evaporated gold. As a result, a much better contact resistance is ensured compared with the previous measurements.

First measurements showed that the samples coated with $\mathrm{PI} /$ NMP $12.5 \mathrm{w} \%$ at a speed higher than $25 \mathrm{~mm} / \mathrm{min}$ were insulating. In Figure 11, an overview is given of the measured leak current of samples coated with $12.5 \mathrm{w} \% \mathrm{PI} / \mathrm{NMP}$ at differing dip-coating speeds of $50,75,100$ and $150 \mathrm{~mm} / \mathrm{min}$. All samples exhibit a leak current in the order of $\mathrm{mA}$, a value that is unacceptably high for the chosen application. Therefore, we assume that the layer is too thin to provide good insulating properties.

Furthermore, we observed that the leak current decreased upon an increasing dip-coating speed. Once a certain threshold value was met, the leak current started to increase again at an increasing speed. The reason for this phenomenon could be the instability in the layer at an increased dip-coating speed. The layer becomes thinner at certain points across the fibre length as described in literature $[41,42]$. Additionally, dip-coating at higher speed increases the risk of crack formation. The gold electrodes make very close contact to the substrate, and any cracks propagating in the $\mathrm{PI}$ layer might result in a strongly increased leak current. This possibility was not considered when using silver paste since this paste did not penetrate into the layer's voids because of the paste's viscosity and silver particle size. Therefore, the silver contacts remained on the surface; cracks in the PI layer therefore did not influence the outcome of the measurements.

Based on previous experiments, we know that to increase the layer thickness, the viscosity and therefore the concentration of dissolved polymer of the solution should be increased. Consequently, the concentration of the PI/NMP solution was increased to $15 \mathrm{w} \%$. The new measurement results show that the leak current is strongly reduced compared with the samples coated from a $12.5 \mathrm{w} \% \mathrm{PI} / \mathrm{NMP}$ solution (see Figure 12). What is also noticed in this test series is that, until a turning point, the leak current decreases at an increasing dip-coating speed. After the turning point, the leak current increases again. Only at a dip-coating speed of $50 \mathrm{~mm} / \mathrm{min}$ was the leak current below the measurable range of $\mathrm{mA}$ detectable with the multimeter.

In comparison with the samples dip-coated in $\mathrm{PI} / \mathrm{NMP}$ solution, the combination with DMF as solvent was tested at a concentration of $15 \mathrm{w} \%$. The results are shown in Figure 13.

In this test series, a similar effect is noticed. At a low dip-coating speed of $12.5 \mathrm{~mm} / \mathrm{min}$, the layer thickness was probably too thin and a high leak current was measured. At a dip-coating speed of $50 \mathrm{~mm} / \mathrm{min}$, the first layer with immeasurable leak current was obtained. At $100 \mathrm{~mm} / \mathrm{min}$, again a slight conduction was observed, probably again due to small cracks in the layer.

Further experiments showed that samples from PI/DMF 17w\% were very slightly conductive when the dip-coating speed was $12.5 \mathrm{~mm} / \mathrm{min}$. Samples treated at higher velocities were insulating over the entire measuring range. The sample coated at $150 \mathrm{~mm} / \mathrm{min}$ exhibited a small, yet measurable leak current of $0.01 \mathrm{~mA}$ when testing at $60 \mathrm{~V}$, indicating again film instability or cracks in the dielectric layer.

\section{Leak current $[\mathrm{A}]$}

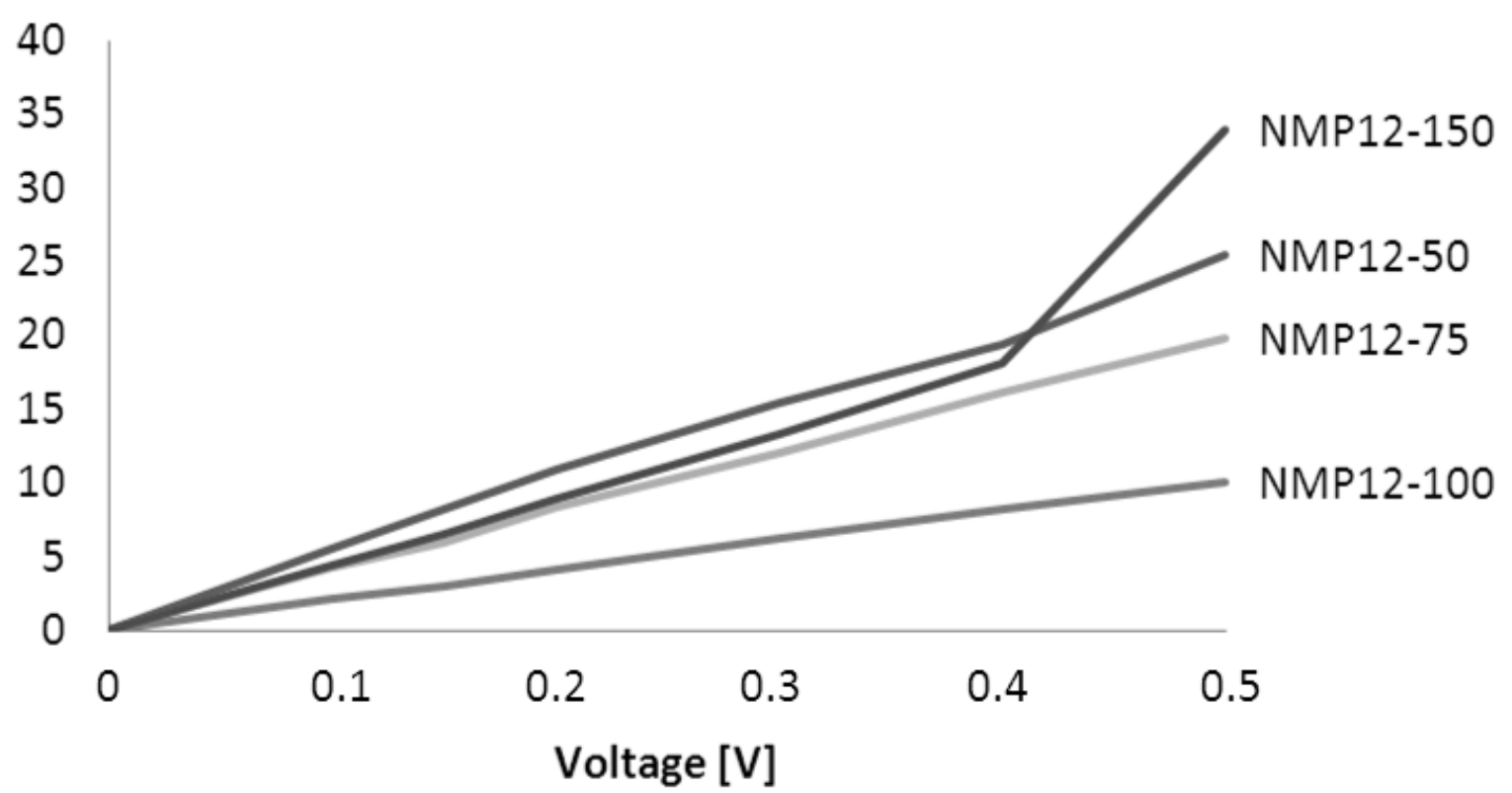

Figure 11. Leak current for samples coated from polyimide/1-methyl-2-pyrrolidone (NMP) $12.5 \mathrm{w} \%$ solution at dip-coating speeds $50,75,100$ and $150 \mathrm{~mm} / \mathrm{min}$. 


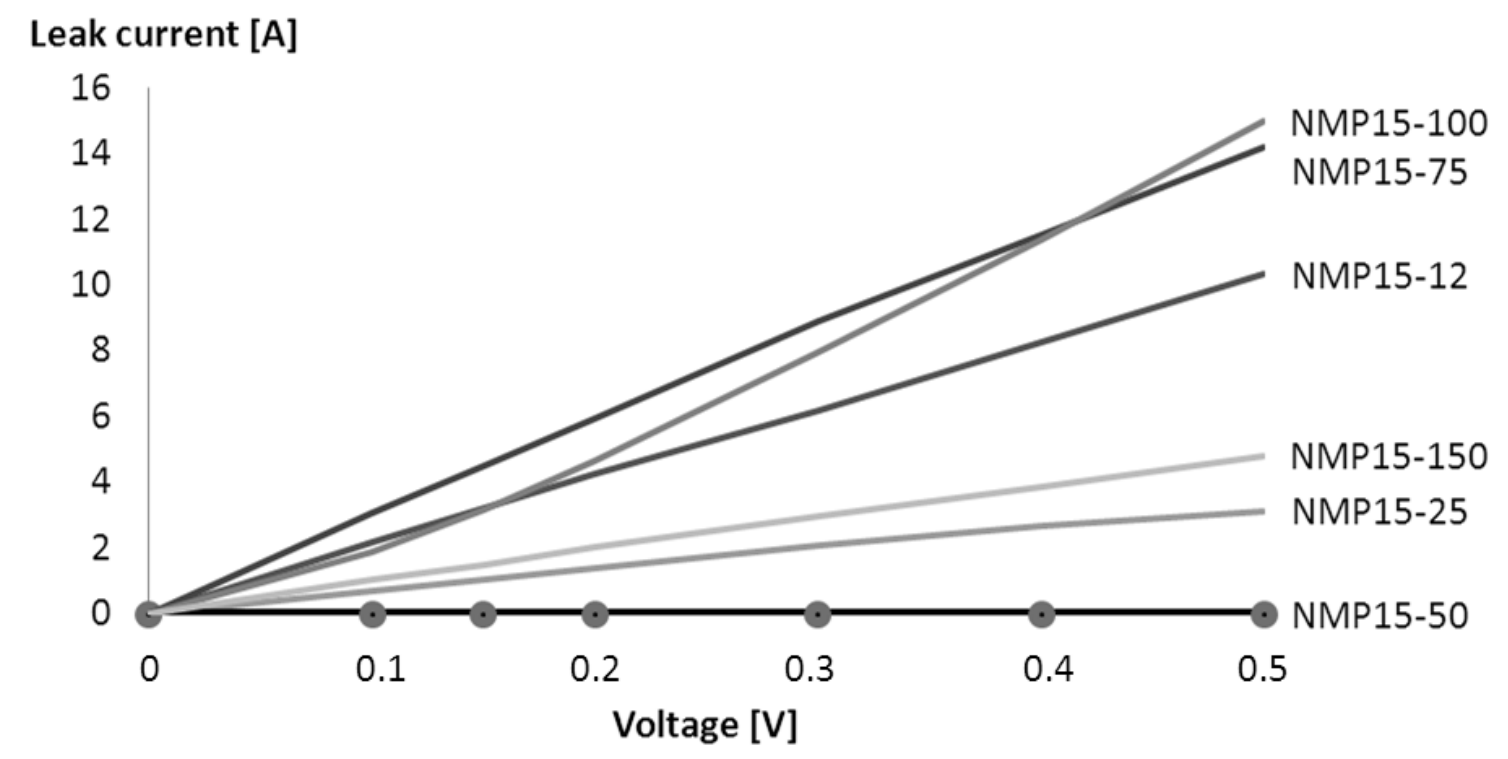

Figure 12. Leak current for samples coated from $15 \mathrm{w} \%$ polyimide/1-methyl-2-pyrrolidone (NMP) solution at dip-coating speed $12.5,25,50,75$, 100 and $150 \mathrm{~mm} / \mathrm{min}$.

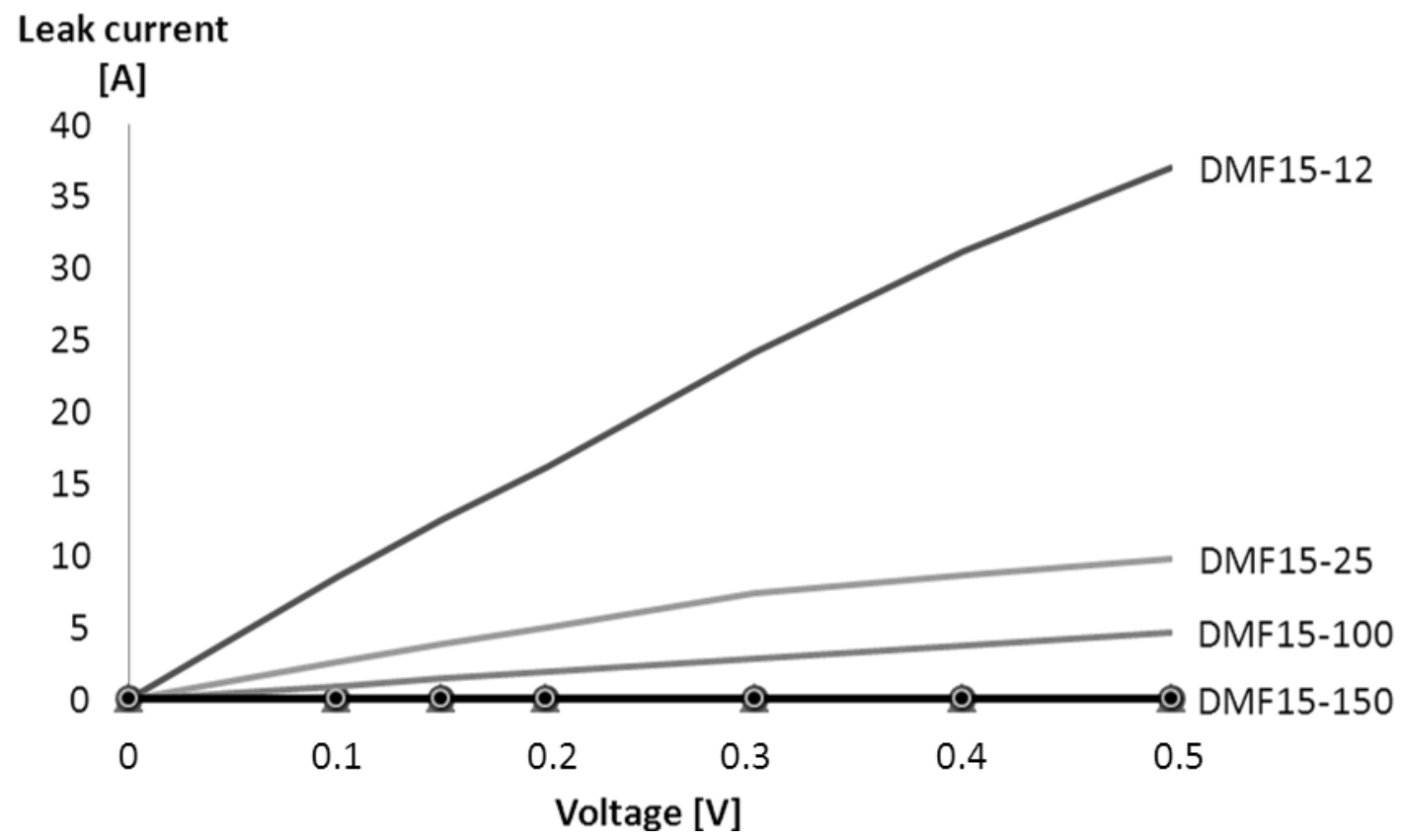

Figure 13. Leak current for samples coated from $15 \mathrm{w} \%$ polyimide/dimethylformaldehyde (DMF) solution at dip-coating speed $12.5,25,50,75$, 100 and $150 \mathrm{~mm} / \mathrm{min}$

For comparison, a commercially available copper wire coated with a $10 \mu \mathrm{m}$ PI layer was tested. The result is shown in Figure 14. The leak current of the copper wire was very high. Therefore, this wire cannot be used for development of a cylindrical shaped transistor. But, when also comparing our sample coated with $\mathrm{PI} / \mathrm{NMP} 12.5 \mathrm{w} \%$ at $50 \mathrm{~mm} / \mathrm{min}$, the layer thickness does not seem to be sufficient. Best results were achieved with a solution concentration of $\mathrm{PI} / \mathrm{NMP} 15 \mathrm{w} \%$ at 50 $\mathrm{mm} / \mathrm{min}$.

In Table 3, an overview is given of the insulating behaviour of different combinations of withdrawal rate and polymer concentration of the dielectric layer coated from both DMF and NMP. The non-shaded fields indicate layers that had a leakage current below the measurable range of $0.01 \mathrm{~mA}$ at $60 \mathrm{~V}$. The shaded fields indicate a significant measured leak current. Corresponding thickness measurements are given in $\mu \mathrm{m}$.

Based on the results shown above, it can be concluded that for a dielectric layer coated from an NMP solution, only the combination of $15 \mathrm{w} \%$ and a $50 \mathrm{~mm} / \mathrm{min}$ withdrawal rate resulted in a sufficiently insulating fibre with a thickness of $600 \mathrm{~nm}$. When DMF was used as a solvent at $15 \mathrm{w} \%$, insulating dielectric layers were obtained for 50 and $75 \mathrm{~mm} / \mathrm{min}$. Also here the ideal thickness was in the order of $600 \mathrm{~nm}$. At PI/DMF $17.5 \mathrm{w} \%$, the fibres coated at 25 and $100 \mathrm{~mm} / \mathrm{min}$ became sufficiently insulating. 


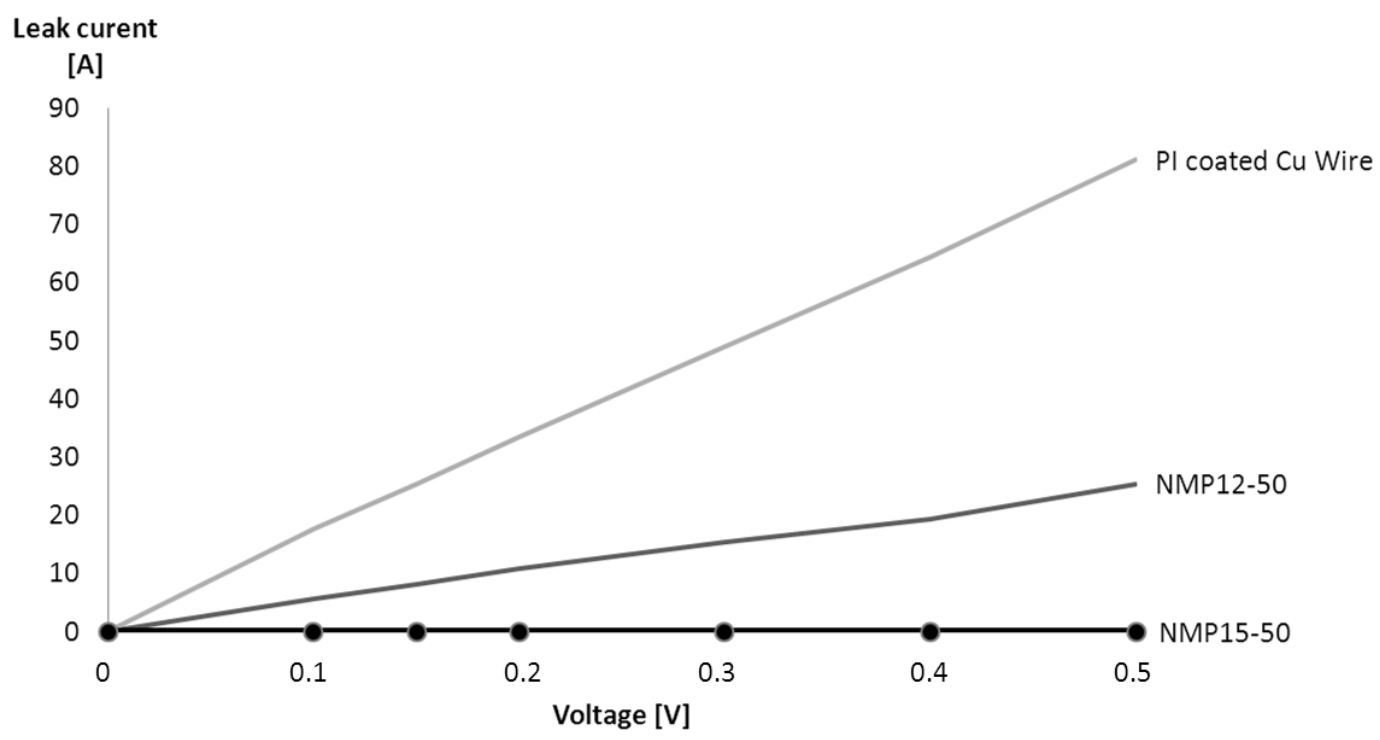

Figure 14. Leak current for samples coated from $12.5 \mathrm{w} \%$ polyimide/1-methyl-2-pyrrolidone (PI/NMP) and $15 \mathrm{w} \% \mathrm{PI} / \mathrm{NMP}$ at $50 \mathrm{~mm} / \mathrm{min}$ versus commercially available PI-coated copper wire.

Table 3. Overview leak current with gold contacts.

\begin{tabular}{|c|c|c|c|c|c|c|c|}
\hline $\begin{array}{c}\mathrm{mm} / \mathrm{min} \\
\text { solvent w\% }\end{array}$ & 12.5 & 25 & 50 & 75 & 100 & 150 \\
\hline NMP 12.5w\% & Leakage & Leakage & 0.64 & 0.71 & 0.75 & 1.07 \\
\hline NMP 15w\% & 0.41 & 0.55 & 0.60 & 0.62 & 0.93 & 0.98 \\
\hline DMF 15w\% & 0.24 & 0.36 & 0.55 & 0.77 & 0.87 & 1.54 \\
\hline DMF 17.5w\% & 0.51 & 0.80 & 1.09 & 1.20 & 1.15 & Leakage \\
\hline
\end{tabular}

DMF, dimethylformaldehyde; NMP, 1-methyl-2-pyrrolidone.

These samples were further examined with HP LF Impedance Analyser 4192A, which can measure up to 10-14 A accuracy. A typical graph for a dielectric leak current was obtained for the samples coated at $50 \mathrm{~mm} / \mathrm{min}$ (PI/NMP 15w\%) (see Figure 15). When plotting $\log (A)$ in function of $\sqrt{ } V$, a linear correlation should be noticed, which is confirmed in Figure 16. Leak current was in the order of 10-9 A. Consequently, this dielectric layer could be used for further development of a transistor on a filament.

As indicated in Figure 17, for the isolating fibres with $15 \mathrm{w} \%$ $\mathrm{PI}$, a leak current in the order of 10-10 A was measured, which is a very good result. Only for $100 \mathrm{~mm} / \mathrm{min}$, a sudden increase in leak current was measured, still well below 10-9 A.

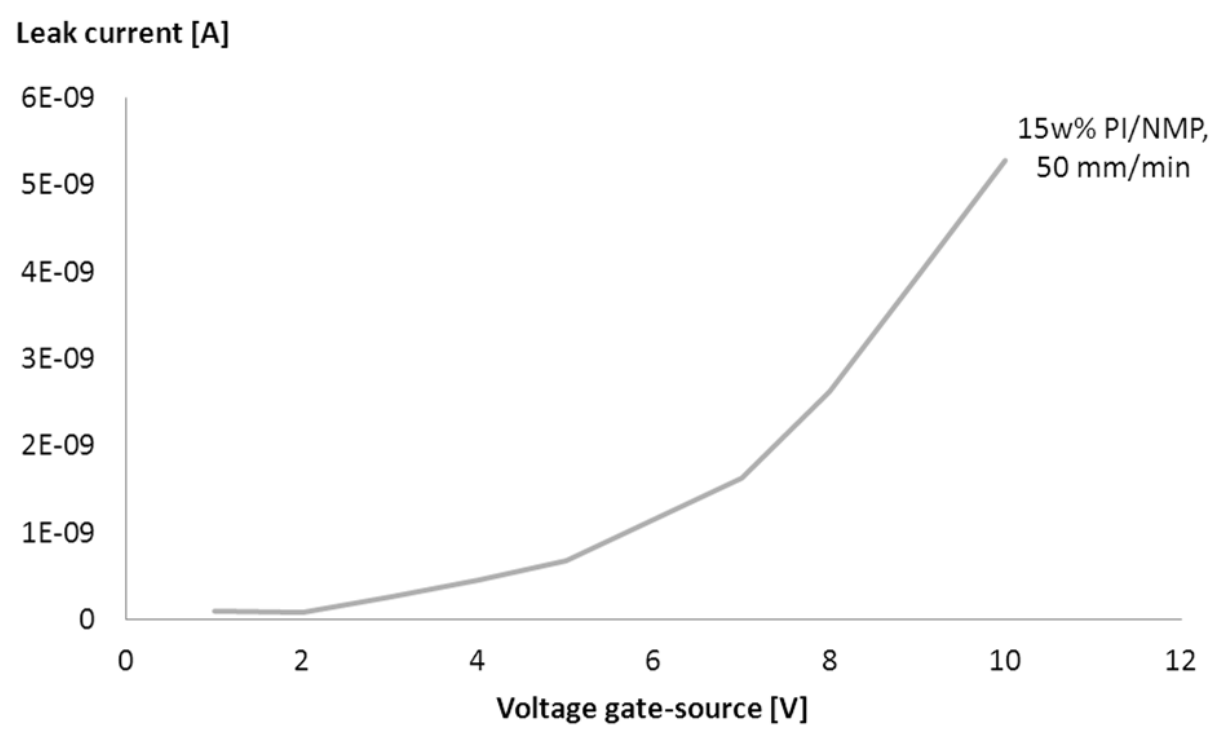

Figure 15. Leak current for samples coated from $15 \mathrm{w} \%$ polyimide/1-methyl-2-pyrrolidone solution at a withdrawal rate of $50 \mathrm{~mm} / \mathrm{min}$. 
$\begin{array}{lc}\text { Leak current } & \text { Voltage gate-source } \\ {[\mathrm{VV}]}\end{array}$

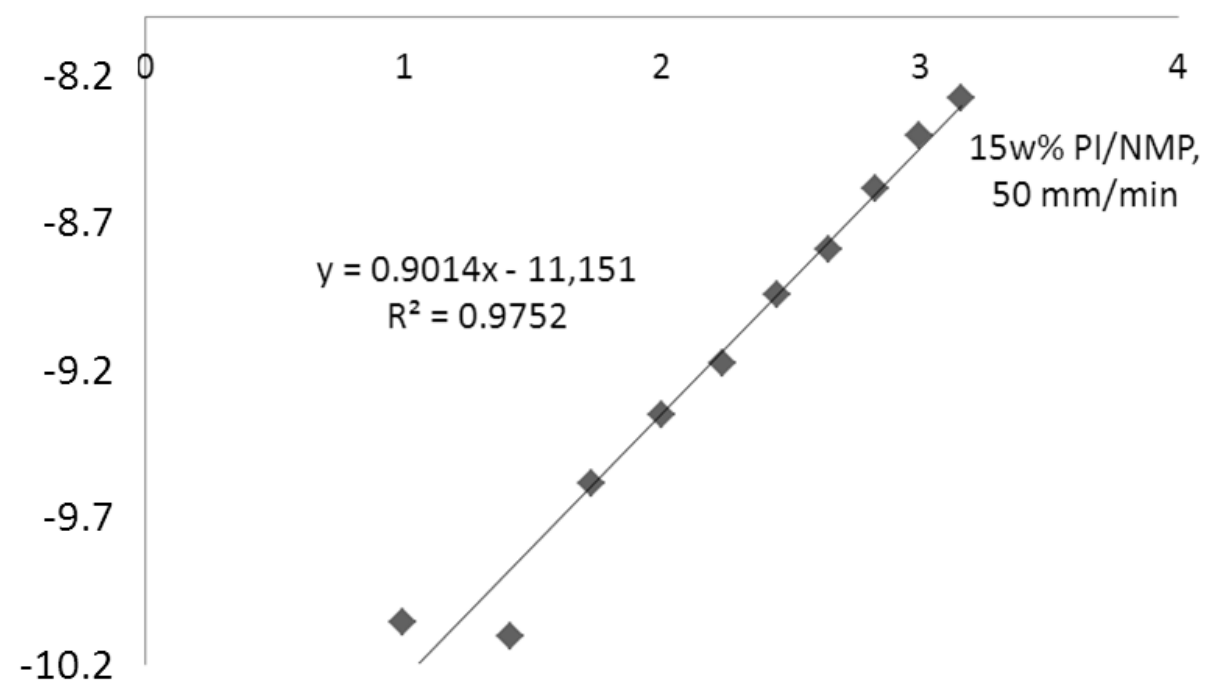

Figure 16. Leak current for samples coated from $15 \mathrm{w} \%$ polyimide/1-methyl-2-pyrrolidone solution at a withdrawal rate of $50 \mathrm{~mm} / \mathrm{min}$ with log (A) in function of $\sqrt{ } \mathrm{V}$.

The leak current is much lower than previously detected with the multimeter. A potential reason could be that a new sample was produced and probably this time no cracks had formed. A higher dip-coating speed leads to an increased layer thickness. Since we target minimal thickness, in any case it is desired to coat fibres at a lower speed. This way, the risk of cracks in the sample should be avoided.

\section{Poole-Frenkel conduction}

From the electrical characterization obtained so far, it is clear that two kinds of PI layers were made. Taking a closer look at the results shown in Figure 11, Figure 12, Figure 13, and Figure 14 , it can be seen that all show a relatively high leakage current. Such PI layers should be considered as electric conductors rather than electric insulating layers. In addition, a leakage current of $10 \mathrm{~mA}$ for an applied voltage of $0.1 \mathrm{~V}$ corresponds to a resistor of $10 \Omega$, which is a rather small value.

Totally different results are shown in Figure 15. First, the IV curve characteristic is no longer linear. Second, the leakage current is several orders of magnitude smaller ( $n A$ instead of $\mathrm{mA}$ range). One can say that the $15 \% \mathrm{PI} / \mathrm{NMP}$ solution with a withdrawal rate of $50 \mathrm{~mm} / \mathrm{min}$ is a good way to obtain good insulation properties. A leakage current of $5 \mathrm{nA}$ for an applied voltage of $10 \mathrm{~V}$ corresponds to a resistor of $2 \mathrm{G} \Omega$.

In order to interpret the results of Figure 15, the same data were plotted again in Figure 16, but using a semilog plot versus $\sqrt{ } \mathrm{V}$. Although the leak current is varying over almost two orders of magnitude (from 10-10 to 10-8), a linear fit was possible. According to the trend line, the experimental IV curve characteristic can be represented by:
One mechanism that explains a relation like (2) is known as the Poole-Frenkel conduction mechanism $[43,44]$. The theoretical formula reads:

$$
I=I_{0} \exp \left[\frac{q}{k \tau} \sqrt{\frac{q V}{\pi \varepsilon_{0} \varepsilon d}}\right]=I_{0} e^{\beta_{F F} V V}
$$

- $d$ = the thickness of the insulating layer

- $V=$ the applied voltage

- $\varepsilon_{0}=8.8510-12 \mathrm{~F} / \mathrm{m}$ : dielectric constant in vacuum

- $\varepsilon=3.5$ : relative dielectric constant of $\mathrm{PI}$

- $k=1.3819-23 \mathrm{~J} / \mathrm{K}$ : Boltzmann constant

- $q=1.610-19 C$ : elementary charge

- $T=$ absolute temperature

- $I_{0}=$ reference current

From Table 3 (NMP 15w\%; $50 \mathrm{~mm} / \mathrm{min}$ ), we learn that the thickness of the PI layer is given by $d=0.6 \mu \mathrm{m}$ so that we get the following numerical value for the Poole-Frenkel coefficient:

$$
\beta_{P F}=\frac{q}{k T} \sqrt{\frac{q}{\pi \varepsilon_{0} \varepsilon d}}=2.0948 \beta_{P F}=\frac{q}{k T} \sqrt{\frac{q}{\pi \varepsilon_{0} \varepsilon d}}=2.0948
$$

This value is remarkably close to the experimental value 2.0755 in (2). Also mentioning the fact that the relation (2) was found to be valid for almost two decades of current values, one may conclude that the observed conduction phenomenon in the $\mathrm{PI}$ layers must be a Poole-Frenkel conduction mechanism.

Another related theory is the Schottky conduction mechanism [45]. The theoretical relationship is now given by:

$I=I_{0} \exp \left[\frac{q}{k \tau} \sqrt{\frac{q V}{4 \pi \varepsilon_{0} \varepsilon d}}\right]=I_{0} \varepsilon^{\left[\beta_{s} \sqrt{V}\right]}$

$I=10^{0.9014 \sqrt{V}-11.151}=7.063110^{-12} 10^{0.9014 \sqrt{V}}=7.063110^{-12} e^{2.0755 \sqrt{V}}$ 
It must be noted that $\beta_{\mathrm{S}}=\beta_{\mathrm{PF}} / 2=1.0474$, a value not in good agreement with our experiments. The main difference between Poole-Frenkel and the Schottky conduction is that PooleFrenkel is a bulk phenomenon whereas the Schottky conduction appears at the electrode contacts. Some authors warn that one should not conclude too quickly that one is dealing with a Poole-Frenkel mechanism as soon as the log $(I)$ versus $\sqrt{ } \mathrm{V}$ plot can be fitted to a straight line. The fitting should be valid for at least one order of magnitude of the current values, which was certainly the case in our experiment.

For the samples coated with $17.5 \mathrm{w} \% \mathrm{PI} / \mathrm{DMF}$ solution, a similar effect was observed as shown in Figure 17 and Figure 18. Because the layer becomes even thicker, a very low leak current was observed. The maximum leak current was measured when the dip-coating speed measured $25 \mathrm{~mm} /$ min. All other dip-coating speeds resulted in a leak current well below $0.1 \mathrm{nA}$.

In the study by Someya et al., a leak current in the order of 10-10 A was obtained for a $500 \mathrm{~nm}$ thick spin-coated PI layer on a flat poly(ethylene naphthalate) substrate. This result is comparable with the leak current obtained in this work on a cylindrical substrate [46].

In general, both higher PI content in solution and higher dipcoating speed lead to thicker layers. Coating at higher speed compared with slower dip-coating speeds therefore results in thicker layers. The choice of solvent also adds to the quality of the layer thickness [36]. DMF evaporates faster and so entrapment of voids, air or humidity can take place leading to thicker layers. The influence of humidity on this layer will be discussed in a subsequent publication.

\section{Conclusions}

We made progress in developing a transistor fibre for application in smart textiles. In this respect, the deposition of PI thin films by dip-coating for application as a dielectric layer in a TopContact-Bottom-Gate OFET architecture was tested, evaluated and optimised. In summary, a range of dip-coating speeds was tested in combination with different solution compositions. The best results and highest insulating properties with a minimum

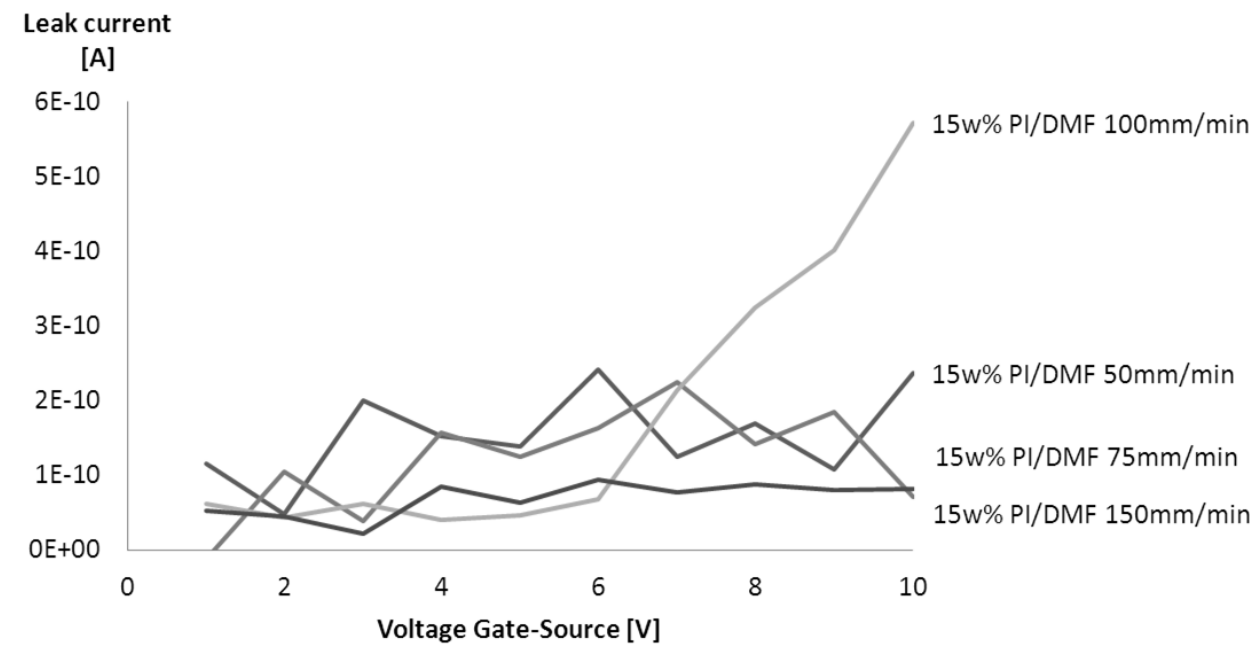

Figure 17. Leak current for samples coated from $15 \mathrm{w} \%$ polyimide/dimethylformaldehyde (PI/DMF) solution.

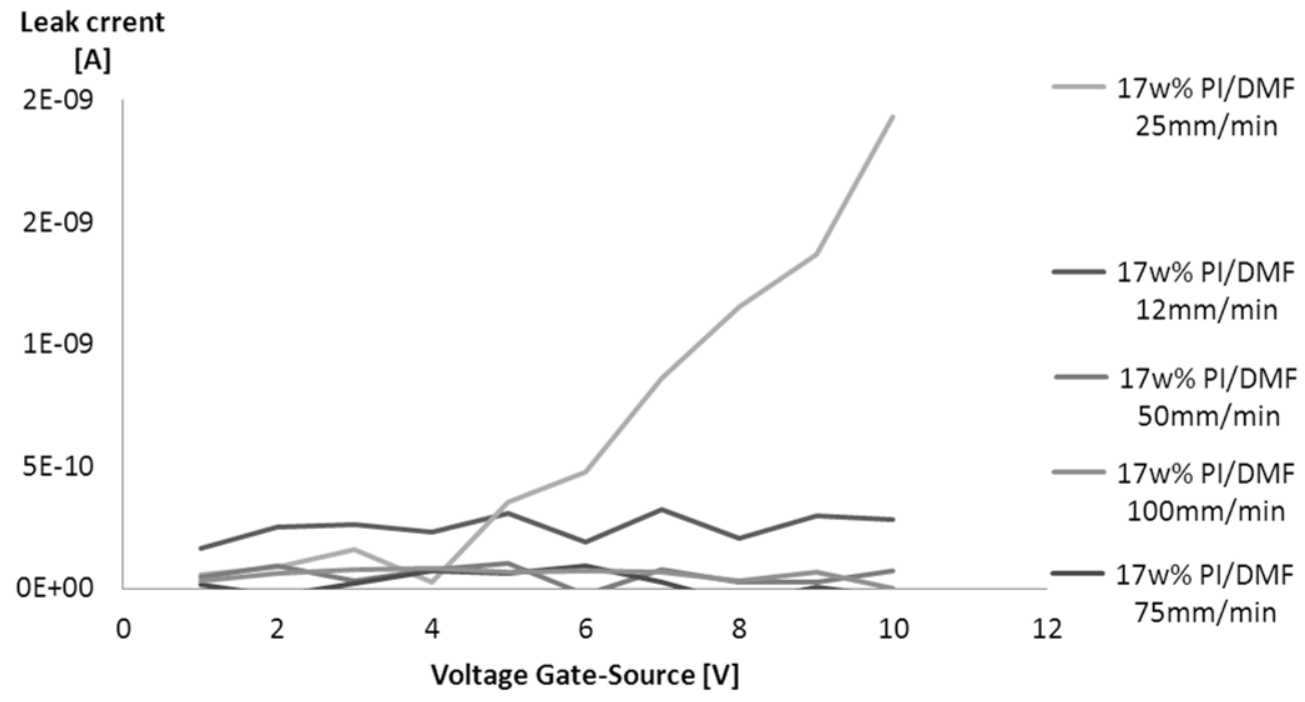

Figure 18. Leak current for samples coated from $17.5 \mathrm{w} \%$ polyimide/dimethylformaldehyde (PI/DMF) solution. 
layer thickness could be achieved at a dip-coating speed of $50 \mathrm{~mm} / \mathrm{min}$ with a $\mathrm{PI} / \mathrm{NMP}$ solution of $15 \mathrm{w} \%$. The results show that the applied layer is insulating from a thickness of approximately $600 \mathrm{~nm}$. The coating was successfully reproduced and the results of the layer's characterisation are presented in this paper. Developing a thin film dielectric layer paves the way for subsequent semiconductor deposition and final completion of OFET architecture on fibrous substrates.

\section{References}

[1] 9GAGInc. Cool non commercialized stuff. 2013.

[2] Flood K. The Original Creators: Diana Dew 2011

[3] GawkerMedia. In The 1960s You Could Wear an Electric Dress. 2008.

[4] Toeters M, ten Bhomer M, Bottenberg E, Tomico O and Brinks G. Research through design: a way to drive innovative solutions in the field of smart textiles. Adv Sci Tech. 2013; 80: 112-7.

[5] Troster G. Smart Clothes-The Unfulfilled Pledge? leee Pervasive Computing. 2011; 10: 87-9.

[6] Weiser M. THE COMPUTER FOR THE 21ST-CENTURY. Scientific American. 1991; 265: 94-\&.

[7] CooperKPand Tms. MATERIALSANDMANUFACTURING CHALLENGES IN HYBRID FLEXIBLE ELECTRONICS. 2010, p.27-40.

[8] Schwarz A, Cardoen J, Westbroek P, et al. Steps Towards a Textile-Based Transistor: Development of the Gate and Insulating Layer. Textile Research Journal. 2010; 80: 173846.

[9] Gao YL. Surface analytical studies of interfaces in organic semiconductor devices. Materials Science \& Engineering R-Reports. 2010; 68: 39-87.

[10] Kwon JH, Seo JH, Shin SI, et al. A 6,13-bis(Triisopropy Isilylethynyl) pentacene thin-film transistor using a spunon inorganic gate-dielectric. leee Transactions on Electron Devices. 2008; 55: 500-5.

[11] Knipp D, Street RA, Krusor B and Ho J. Pentacene thin film transistors and circuits: Influence of processing and device design. In: Jabbour GE, Carter SA, Kido J, Lee ST and Sariciftci NS, (eds.). Organic and Polymeric Materials and Devices-Optical, Electrical and Optoelectronic Properties. 2002, p. 131-6.

[12] Feili D, Schuettler M, Doerge T, Kammer S, Hoffmann $K P$ and Stieglitz T. Flexible organic field effect transistors for biomedical microimplants using polyimide and parylene $C$ as substrate and insulator layers. Journal of Micromechanics and Microengineering. 2006; 16: 155561.

[13]PROETex. D8.1 Report on fibre design for different electronic functions (transistors, sensors). 2007.

[14]Zhou LR, Wu GN, Cao KJ, Luo Y and leee. Study on Charge Transport Mechanism in Polyimide Films. 2009, p.800-3.

[15] Facchetti A, Yoon $\mathrm{MH}$ and Marks TJ. Gate dielectrics for organic field-effect transistors: New opportunities for organic electronics. Adv Mater. 2005; 17: 1705-25.

[16] Quevedo-Lopez MA, Wondmagegn WT, Alshareef HN, Ramirez-Bon $R$ and Gnade BE. Thin Film Transistors for Flexible Electronics: Contacts, Dielectrics and
Semiconductors. J Nanosci Nanotechnol. 2011; 11: 55328.

[17] Lee SC, Tai FC, Wei CH and Yu JI. ATR-FTIR and nanoindentation measurements of PMDA-ODA polyimide film under different curing temperature. Materials Transactions. 2007; 48: 1554-7.

[18] Youngs IJ, Stevens GC and Vaughan AS. Trends in dielectrics research: an international review from 1980 to 2004. Journal of Physics D-Applied Physics. 2006; 39: 1267-76.

[19] Bonfiglio A, De Rossi D, Kirstein T, et al. Organic field effect transistors for textile applications. leee Transactions on Information Technology in Biomedicine. 2005; 9: 31924.

[20] Cardoen J. Ontwikkeling van transistor vezels. Master Thesis Universiteit Gent. 2007.

[21] Ree M. High performance polyimides for applications in microelectronics and flat panel displays. Macromolecular Research. 2006; 14: 1-33.

[22] wikipedia. Wet Processing Engineering. 2013.

[23] DuPont. Kapton® polyimide film. 2012.

[24] AlfaAesar. Product Bulletin, Stock \#43656. 2013: 1.

[25] Kiekens P. Advanced and Specialised Fibrous Materials. Ghent, Belgium: Universiteit Gent, 2008.

[26] Jung KD, Kim YC, Shin $H$, et al. A study on the carrier injection mechanism of the bottom-contact pentacene thin film transistor. Applied Physics Letters. 2010; 96.

[27] Kim JH, Min BR, Won J, Park HC and Kang YS. Phase behavior and mechanism of membrane formation for polyimide/DMSO/water system. Journal of Membrane Science. 2001; 187: 47-55.

[28]Guo MC and Wang XG. SYNTHESIS AND CHARACTERIZATION OF POLYIMIDE WITH MAINCHAIN PHOTOSENSITIVE GROUPS AND HYDROXYL SIDE-GROUPS. Acta Polym Sin. 2008: 1113-7.

[29] Guo MC, Li SN, Wang XG, Liu G and Yi XS. SYNTHESIS AND CHARACTERIZATION OF A POLYIMIDE CONTAINING PHENOLPHTHALEIN GROUPS. Acta Polym Sin. 2012: 278-83.

[30] Ren HF, Guan Y, He YN, He HF and Wang XG. Polyimide containing isosorbide units: Synthesis and characterization. Acta Polym Sin. 2006: 248-52.

[31] Maccioni M, Orgiu E, Cosseddu P, Locci S and Bonfiglio A. Towards the textile transistor: Assembly and characterization of an organic field effect transistor with a cylindrical geometry. Applied Physics Letters. 2006; 89.

[32] Bormashenko E, Pogreb R, Stanevsky O, et al. Mesoscopic and submicroscopic patterning in thin polymer films: Impact of the solvent. Materials Letters. 2005; 59: 2461-4.

[33] wikipedia. Chemical Solution Deposition. 2013.

[34] Arfsten NJ, Eberle A, Otto J and Reich A. Investigations on the angle-dependent dip coating technique (ADDC) for the production of optical filters. Journal of Sol-Gel Science and Technology. 1997; 8: 1099-104.

[35] Van Genabet B. Synthesis and characterisation of copper, polyimide and TIPS-pentacene layers in the development of a solution processed fibrous transistor. Department of Textiles. Gent: Universiteit Gent, 2010.

[36] Yong-Hoon K, Lee YU, Jeong-In H, Han SM and Han MK. Influence of solvent on the film morphology, crystallinity 
and electrical characteristics of triisopropylsilyl pentacene OTFTs. Journal of the Electrochemical Society. 2007; 154: H995-H8.

[37] Kim J, Jeong J, Cho HD, et al. All-solution-processed bottom-gate organic thin-film transistor with improved subthreshold behaviour using functionalized pentacene active layer. Journal of Physics D-Applied Physics. 2009; 42.

[38] Choi MH, Han SH, Lee SH, Choo DJ, Jang J and Kwon SK. Effect of active layer thickness on environmental stability of printed thin-film transistor. Organic Electronics. 2009; 10: 421-5.

[39] Mikhailenko SUD, Wang KP, Kaliaguine S, Xing PX, Robertson GP and Guiver MD. Proton conducting membranes based on cross-linked sulfonated poly(ether ether ketone) (SPEEK). Journal of Membrane Science. 2004; 233: 93-9.

[40]Adachi $T$ and Sakka S. THE ROLE OF N,NDIMETHYLFORMAMIDE, A DCCA, IN THE FORMATION
OF SILICA-GEL MONOLITHS BY SOL-GEL METHOD. J Non-Cryst Solids. 1988; 99: 118-28.

[41] Schwarz A. Analysis of wetting behaviour of an inclined fibre. Kaunas: Kaunas University of Technology, 2005.

[42] Quere D, Dimeglio JM and Brochardwyart F. SPREADING OF LIQUIDS ON HIGHLY CURVED SURFACES. Science. 1990; 249: 1256-60.

[43] C.Hemenway/R.Henry/M.Caulton. Physical electronics. New York: Wiley 1967.

[44] Frenkel J. On pre breakdown phenomena in insulators and electronic conductors. Physical Review, 1938.

[45] L.Solymar/D.Wals. Electrical properties of materials 6th ed. Oxford: Oxford university press, 1998, p.90-2.

[46] Someya T, Sekitani T, Iba S, Kato Y, Kawaguchi $H$ and Sakurai T. A large-area, flexible pressure sensor matrix with organic field-effect transistors for artificial skin applications. Proceedings of the National Academy of Sciences of the United States of America. 2004; 101: 9966-70. 